EGU21-11559, updated on 18 Aug 2021

https://doi.org/10.5194/egusphere-egu21-11559

EGU General Assembly 2021

(c) Author(s) 2021. This work is distributed under

the Creative Commons Attribution 4.0 License.

\title{
Tourmalinisation in peraluminous granitic context : from experiment to thermodynamic modelling
}

\author{
Julien Fort ${ }^{1}$, Stanislas Sizaret ${ }^{1}$, Michel Pichavant ${ }^{1}$, Arnault Lassin ${ }^{2}$, Johann Tuduri ${ }^{2}$, and Olivier \\ Blein ${ }^{2}$ \\ ${ }^{1}$ Institut des Sciences de la Terre d'Orléans (ISTO), UMR 7327, CNRS/BRGM, Université d'Orléans, 45071, Orléans, France \\ ${ }^{2}$ Bureau de Recherches Géologiques et Minières (BRGM) - France
}

Tourmaline records the physico chemical conditions during its cristallisation, as its primary chemical zonations are generally unbalanced, its occurrence as alteration product could be used to decipher the physicochemical properties of mineralizing fluids. However, the role of the tourmalinisation in hydrothermal processes remains little studied, if not poorly understood. The complexity of its thermodynamic properties is related to the presence of four cationic sites allowing the accommodation of a wide variety of elements (Henry and Dutrow, 2018). Moreover the phenomena of deprotonation, $\mathrm{Si}^{-{ }^{1} \mathrm{~B}} \mathrm{~B}$ and valence state, make the approach of solid solution properties complex (Hughes et al., 2001; Henry et al., 2011; Bačík, 2015; Morgan, 2016). Thus, thermodynamic properties are most often estimated (Garofalo et al., 2000; Hinsberg and Schumacher, 2007) and only a few measurements could be carried out on a reduced number of near-endmembers crystals (Kuyunko et al., 1984; Ogorodova et al., 2012).

This study aims to investigate experimentally the stability field of schorl ( $\mathrm{Na}-\mathrm{Fe}$ ) - dravite ( $\mathrm{Na}-\mathrm{Mg}$ ) solid solution at $2 \mathrm{kbar}$ total pressure between $400^{\circ}$ and $600^{\circ} \mathrm{C}$ as a function of the boron content of the fluid and fO2 condition, using an internally heated gas apparatus. Those metasomatic experiments have been conducted on a mixture of naturals crystals of cordierite + albite, representing a peraluminous granite composition in a Na-Mg-Fe-Al-Si-B-O-H system, characterized by a high-Mg, low-Fe content. These experiments were performed in order to simulate a classic aluminous host of these tourmaline alterations in granitic context. The results will be studied, in terms of stability of the tourmaline species, chemistry variation and texture. They will be compared with thermodynamic models build using data from the literature (Korges et al., 2018; Pan et al., 2019 among others) . Ultimately, the objective is to characterize in a P, T, W/R space, the chemical evolution of fluids, the alteration sequence of rocks and the variations in volumes related to the successive reactions. 